Revista de Ensino em Artes, Moda e Design

\title{
Dossiê 3
}

Novas perspectivas de aprendizagem

\section{ENSINO DA INCLUSÃO NA MODA: UMA PROPOSTA PEDAGÓGICA ORIENTADA PELAS CONQUISTAS DE CÓRDOBA E DO ADEUS AO TRABALHO}

\section{Fashion education for inclusion: a pedagogical proposal oriented by the Córdoba's conquests and the Goodbye at work}

\section{Emanuella Scoz ${ }^{1}$}

\section{Niguelme Cardoso Arruda ${ }^{2}$}

\footnotetext{
1 Pesquisadora CAPES (2018), Mestranda em Educação pela Fundação Universidade Regional de Blumenau- FURB (2018), Especialista em Negócios da Moda pelo Instituto brasileiro de Moda- IbModa (2009) e Designer de Moda pelo Centro Universitário Leonardo Da Vinci (2006). E-mail: emanuella_design@hotmail.com - Lattes: http://lattes.cnpq.br/3858787418552795

2 Doutorado em Linguística e Língua Portuguesa pela Universidade Estadual Paulista Júlio de Mesquita Filho, Brasil (2012), (Doutorado Sanduíche)- junto à Universidad Autónoma de Madrid. Mestre em Linguística e Língua Portuguesa, pela UNESP-Araraquara, (2006). Possui especialização em Educação pela Universidade do Estado de Minas Gerais (2000) e em Linguística Aplicada pela Universidade Federal de Uberlândia (2002). Graduado em Letras pela Universidade Federal de Goiás (1996). 


\title{
Resumo
}

Este artigo aborda o ensino da inclusão na Moda a partir de atividade iniciada em Maio de 2017, com estudantes de Moda. Concluída em seis meses, tendo participação da equipe de para desporto de Blumenau, foi baseada nos princípios da reforma de Córdoba, objetivando refletir o ensino da inclusão na Moda, e a ação profissional. Influenciada pelas transformações no mundo do trabalho da obra Adeus ao Trabalho (ANTUNES, 1995, 2015), foi considerada melhor projeto inovador pelo INOVA SC 2017, após transformar-se com autoria dos discentes. Na mudança de percurso eles compreenderam a existência de uma Moda exclusiva e segregadora, incluíram ao desenvolvimento das peças: portadores de necessidades e síndromes diversas, idosos e pessoas com debilidade motora. O resultado final foi uma coleção com roupas possível de uso por qualquer pessoa e vendidas em qualquer magazine, aplicando o verdadeiro sentido da palavra inclusão.

Palavras-Chave: Inclusão na Moda; Reforma de Córdoba; Trabalho.

\begin{abstract}
This article means about inclusion in Fashion, using an activity started in May 2017, with students of a Fashion course. Completed in six months, had participation of a Blumenau's physical disabilities staff, and was based on Cordoba's reform, purposing to reflect the teaching of inclusion, and the professional actions. Influenced by the Goodbye to Work (ANTUNES, 1995) was considered the best innovative project by INOVA SC 2017 , after being transformed for the students. In the change of course, they understood that Fashion exclude and segregating, so included in the collection: syndromes, elderly and people with motor impairment. The result was a collection of clothes that could be worn by anyone and sold in any magazine, applying the true meaning of the word inclusion.
\end{abstract}

Keywords: Córdoba's Reform; Inclusion of Fashion; Work. 


\section{INTRODUÇÃO}

No ano do centenário de Córdoba, resgatar os objetivos adquiridos com a reforma e demonstrar sua originalidade ainda nos dias atuais pareceu tentador. Ao defender uma universidade livre, igualitária e não hegemônica, os estudantes de Córdoba em 1918 nos deram de presente um modelo que, se aplicado às práticas pedagógicas, nos auxiliam na formação de profissionais responsáveis e cientes da utilidade de seu trabalho. Quando compartilham suas realidades regionais com o coletivo, os estudantes sentem fazer sentido o conteúdo formativo aplicado e seu papel social.

Para Delgado (2010, p.156) o curso de Moda, seja na modalidade bacharel ou ensino técnico, possui "associação direta ao chamado "setor produtivo", ou seja, criação, desenvolvimento de processos e produtos, cabendo a tais cursos garantir a "competência profissional", segundo a LDB 9394/96 e CNE/CP 29/2002". Sendo assim, necessitamos de um olhar apurado para o ensino da Moda, não só para o mercado ou mundo do trabalho, mas para as ações sociais do trabalho.

Santos (2010) afirma ser necessário uma perspectiva positiva sobre a economia, abrindo possibilidade de ascensão para novas economias em desenvolvimento, como as que utilizam da cultura e da criatividade. A economia criativa da Moda vem ascendendo e exige novos olhares.

Para permitir a formação integral do profissional de Moda, em plena era da informação, a universidade não é mais transmissora do conhecimento, tem agora o papel de permitir que este seja criado e compartilhado. Desta forma, as atividades aplicadas aos conteúdos formativos devem ser repensadas para fazer sentido às realidades vividas e conhecidas, ampliando cada vez mais as capacidades discentes. Na sociedade moderna a formação profissional deve preocupar-se para além das questões técnicas, sociabilizando o trabalho e humanizando o profissional.

Antunes (1995) trata o trabalho como uma forma de integração humana, e motor das transformações sociais. $O$ ensino profissionalizante, compreendido aqui por ser não apenas o ensino técnico, mas todo ensino voltado a capacitar o ser para alguma atividade laborativa, encontra-se diretamente ligada ao papel do indivíduo na sociedade, amparado pelo valor de seu trabalho. Esse papel necessita ser bem compreendido pelo estudante, a fim de que possa, em seu momento, transpor suas características pessoais por meio do trabalho na sociedade.

Pires (2007) já questionava a formação profissional, em relação, por exemplo, as questões estéticas vinculadas ao currículo, indicando que este, por determinantes históricos, influenciava uma concepção excludente em relação aos biótipos e idades marginalizando uma faixa da população.

O público alvo que podemos observar pelas peças expostas nas vitrines não aparenta sofrer de transtornos alimentares, ou doenças crônicas, condições genéticas variadas, ou ter alguma redução na mobilidade. Aparentemente, os nichos de mercado criaram um padrão automático de corpo que segrega boa parte da população. De fato, não é este papel excludente que se deseja formar nos profissionais que irão preencher as esferas sociais.

Este artigo aborda o ensino da inclusão na Moda a partir de atividade iniciada em Maio de 2017, com estudantes de Moda de uma escola técnica em Blumenau, foi 
concluída em seis meses, e durante o processo obteve a participação da equipe de para desporto de Blumenau, baseada nos princípios da reforma de Córdoba de ensinar para a sociedade.

O objetivo da atividade era refletir o ensino da inclusão na Moda, e a ação profissional. Influenciada pelas transformações no mundo do trabalho da obra Adeus ao Trabalho (ANTUNES, 1995, 2015), compreendemos que o trabalho é social, na geração de conhecimento dentro das universidades, apoiamo-nos nas necessidades reais das pessoas.

O atividade foi considerada melhor projeto inovador pelo INOVASC 2017, contexto fora dos objetivos iniciais e que só foi possível após transformar-se completamente por autoria dos discentes. A mudança de percurso ocorreu após eles compreenderam a existência de uma Moda exclusiva e segregadora, então, incluíram ao desenvolvimento das peças: pessoas portadores de necessidades e síndromes diversas, idosos e pessoas com debilidade motora.

O resultado final foi uma coleção com roupas possível de uso por qualquer pessoa e vendidas em qualquer magazine, aplicando o verdadeiro sentido da palavra inclusão.

Espera-se contribuir com as discussões sobre a práxis da Moda, inserindo o ensino da inclusão na educação de Moda, reconhecendo as necessidades especiais não como um nicho de mercado, mas como uma realidade cotidiana.

\section{A FORMAÇÃO HUMANA PARA O TRABALHO}

A Reforma de Córdoba de 1918 na universidade de Córdoba, na Argentina, representa a luta e conquista da classe estudantil, que, percebeu-se excluída e marginalizada, questionava a hierarquia e reivindicava uma universidade preocupada com os aspectos sociais da comunidade. O manifesto escrito pelos estudantes em 21 de Junho de 1918 inicia com a frase "Da Juventude Argentina de Córdoba aos homens livres da América" (CMI, 2007), e o texto completo é um poema, explorado por Neto (2011) e aplicado no decorrer deste texto.

Neto (2011, p.66) afirma que: "Se não existe uma vinculação espiritual entre o que ensina e o que aprende, todo ensinamento é hostil e, consequentemente, infecundo", esta era uma das afirmações estudantis durante a reforma de Córdoba em 1918. Como espiritual pode-se compreender que o que se ensina deve estar ligado ao espírito humano, sua essência de vida e necessidade. O aprendizado necessita de significado, para que seja proveitoso e profícuo, ressignificando o próprio estudante em sua atuação social.

O trabalho, para Antunes (2015a) é, mais que uma ação do homem, o motivo de sua organização e motor social. Desta forma, a educação formadora para o trabalho está diretamente responsável pela formação do social e inserção do indivíduo no meio. A prática pedagógica não pode desvincular-se destas duas concepções: de que o ensino deve ter vinculação com o ser, e de que o trabalho é o motor social (ANTUNES, 1995).

Antunes (1995, p.82) coloca que "enquanto criador de valores de uso, coisas úteis, forma de intercâmbio entre o ser social e a natureza, não parece plausível conceber-se, no universo da sociabilidade humana, a extinção do trabalho social". Compreen- 
demos que o trabalho, integrando e sociabilizando, é indissociável da ação e utilização humana, cada produto criado tem utilidade e significação social, não faz sentido render os objetos de nossa criação a meros expoentes estéticos, sem função social ou função humana.

A Moda anda paralela à sociedade, transformam-se dela e para ela, como construção social acompanha os movimentos sociais, que para Frank e Fuentes (1989, p.26) "são cíclicos". Podemos dizer que a Moda educa tanto quanto a educação massifica. A Moda, no entanto, sempre esteve ligada, no Brasil, as cadeias de produção e industrialização, enquanto a educação mantém-se como produção do intelecto e do ser sociável.

Pires (2007) cita que ainda restam desafios a serem superados pela educação para Moda "que consolide uma nova cultura de projeto dos bens de consumo para o corpo" (PIRES, 2007, p.81) no desenvolvimento de produtos, sistemas e serviços, ampliando o acesso à estética da Moda pensando nela sob a ótica da justiça social, economia e sustentabilidade ambiental.

O desejo de uma Moda ética e responsável inicia na sala de aula. Compor o aprendizado com informação de mundo e sociedade, vinculando o social ao trabalho é função primordial de uma educação para cidadãos críticos e responsáveis. Não nos adianta criticar o profissional, se este não recebeu em sua formação a base para lidar com a função e necessidades humanas.

$\mathrm{Na}$ Moda atualmente, muitas vezes, a criação é feita para seres imaginários que representam públicos alvos observados em tendências de Moda, no entanto, quem veste a roupa é o público que nos circunda, vive e respira conforme suas condições. $A$ realidade que escapa da Moda no trabalho cotidiano é refletida nas vitrines cheias do mesmo, e na diferenciação das pessoas entre nichos ou sub culturas.

Em Córdoba defendeu-se uma juventude que apoiava que a universidade soubesse lidar com as transformações culturais, acompanhando a realidade do cotidiano, adquirindo e transferindo cidadania, ao trabalhar os planos culturais e sociais, econômicos e filosóficos, éticos, em acordo com uma identidade própria, sem adquirir a identidade de outra nação, criando, e não mais assimilando valores e padrões de estética.

José Ingenieros (1877-1925) que defendia ser a juventude a protagonista das transformações culturais, além de ser um árduo entusiasta de que a nacionalidade argentina estava por ser construída nos planos ético, cultural, social, econômico e filosófico e a Universidade deveria acompanhar tal debate, distanciando-se de um modelo europeu e adquirindo feições próprias (NETO, 2011, p.67)

Este processo só é possível, no ensino de Moda, se repensarmos também a Moda. Neste sentido, a reforma de Córdoba nos auxilia a repensar a práxis. A universidade aberta ao povo, defendida pela reforma, nos incute que, o que se aprende e o que se ensina deverá também ser aberto ao povo. A busca por autonomia, democratização e a abertura da produção e circulação do conhecimento (NETO, 2011) defendida pela reforma é trazida para a prática pedagógica de forma a permitir o ensino emancipatório para o profissional em sua realidade.

Em entrevista sobre sua obra "Adeus ao Trabalho", Antunes (2015b, p.778) citava que "nosso problema é compreender o novo desenho da classe trabalhadora, a 
nova morfologia do trabalho, e nós temos que entender a classe--que-vive-do-trabalho hoje". Onde a nova classe trabalhadora, tratada como novo proletariado, são pessoas que não participam unicamente da produção industrial, mas do trabalhador assalariado prestador de serviços.

Ao mesmo tempo que trata da precarização do trabalho global, Antunes (2015b) remete às novas concepções de trabalho, dos quais podemos conceber que, sendo o ensino de Moda no Brasil basicamente profissionalizante, necessita ater-se aos novos rumos do trabalho.

Iniciando com a visão das latentes transformações profissionais, das crescentes necessidades de conscientização social da Moda, projetava-se em 2017 uma atividade com objetivo de permitir autonomia, democratização e conscientização social, com a coautoria de estudantes e coparticipação de demais professores. Nascia o projeto Inclusão na Moda. Que é trazido aqui para expor e questionar, a partir das conceituações geradas durante o projeto, a prática do design de Moda atual, que segrega e desqualifica, muitas vezes, mais do que humaniza e profissionaliza.

\section{ENSINO dA INCLUSÃo NA MOdA: A PROPOSTA PEDAGÓGICA}

Em Maio de 2017, ao lecionar para uma turma de ensino profissionalizante de uma escola técnica em Blumenau, percebi que, em relação ao desenvolvimento de produto, os estudantes viam-se desmotivados, eles desenvolviam peças aparentemente sem sentido além do estético. Enquanto educadora e profissional da área de Moda refleti sobre o papel da Moda, sobre qual era a necessidade de criar roupas para seres de carne e osso. Assim, propus uma atividade que refletisse sobre a prática de desenvolver produtos de vestuário.

A atividade necessitava relacionar o desenvolvimento das peças às necessidades de uso da roupa, para compreensão de aspectos como vestibilidade e usabilidade. O aspecto estético viria a ser considerado, ao final do processo de pensar a roupa para o ser humano. Para caracterizar a utilidade da roupa no nosso cotidiano, o desenvolvimento dessa atividade teve a participação da comunidade, através da equipe de para desporto da cidade, da instituição, unindo professores e contando com o auxílio constante da equipe pedagógica, e da turma, a partir da coparticipação dos estudantes na condução do trabalho.

Foi um longo trabalho em que me questionava, como docente, como possibilitar àquelas pessoas que seriam um dia profissionais de Moda a oportunidade de vislumbrar a realidade nua e crua de sua funcionalidade cotidiana? A atividade proposta visava construir, descontruir ou reconstruir significados sobre o trabalho do designer de Moda. Foi uma proposta pedagógica que visava gerar conhecimento a partir da visão dos estudantes sobre as questões do design e da Moda, e oportunizar a eles definir sua responsabilidade no trabalho que, no fim das contas, é social além de técnico.

Antunes (1995, p.86) já traduzia que "quando a defesa da sociedade do mercado e do capital não é claramente explicitada nestas formulações (do trabalho concreto e abstrato), resta a proposição utópica e romântica do tempo livre no interior de uma sociedade fetichizada". A divisão entre trabalho social e trabalho concreto dificulta conceber o que é o ser real do que é imaginário, o ser social é um ser real, e o trabalho é uma 
atividade de utilidade pública, havendo a necessidade de instruir sobre a vinculação do social no trabalho, para não carecermos de utilidade em nossas ações cotidianas, fetichizando um tempo livre cheio de alegrias, e um tempo de trabalho cheio de obrigações desnecessárias. "A discussão que nos parece pertinente é aquela que reconhece, de um lado, a possibilidade da emancipação do e pelo trabalho, como um ponto de partida decisivo para a busca da omnilateralidade humana." (ANTUNES, 1995, p.88).

Os alunos, questionados sobre a função social da roupa e o real significado de usabilidade e vestibilidade, a partir de suas experiências pessoais com a roupa e experiências de pessoas conhecidas, como o intuito de abrir discussão para os biótipos, compreenderam que a Moda, como cultura traduzida em nosso vestuário, ainda não era acessível a uma parcela grande da população que, ao sofrer a experiência da compra, muitas vezes, não se via atendida em suas necessidades básicas de usar e vestir. A proposta então migrou para o questionamento sobre a inclusão, a partir das experiencializações dos próprios estudantes, do seu cotidiano em torno da roupa que permeia a vida.

A reforma de Córdoba é contextualizada por todo um processo de domínio cultural nas colônias que acometeu a toda a América Latina (NETO, 2011). O ensino intelectual para as elites e o ensino braçal para as classes baixas, o não acesso proposital criado para as classes baixas ao ensino intelectual e a utopia da meritocracia marcaram, até hoje, a estigma de trabalho que vincula uma obrigação e não necessidade de raciocinar sobre o que se produz.

A revolução de nossos dias é, desse modo, uma revolução no e do trabalho, na medida em que deve necessariamente abolir o trabalho abstrato, o trabalho assalariado, a condição de sujeito-mercadoria, e instaurar uma sociedade fundada na auto atividade humana, no trabalho concreto que gera coisas socialmente úteis, no trabalho social emancipado. Mas é também uma revolução do trabalho, uma vez que encontra no amplo leque de indivíduos (homens e mulheres) que compreendem a classe trabalhadora, o sujeito coletivo capaz de impulsionar ações dotadas de um sentido emancipador. (ANTUNES, 1995, p.88).

A reforma de Córdoba foi inspiração para os movimentos estudantis de 1933 no Brasil, e é atual até hoje, em seus princípios de democratizar o ensino e integrar a instituição à comunidade, o que traz sentido e significado ao ensino proposto. Antes das propostas estudantis:

Mantinha-se um ensino dogmático, com a repetição exaustiva dos mesmos textos e programas, impedindo o desenvolvimento da ciência e a introdução de "disciplinas modernas". A estrutura administrativa e burocratizada, fechada em si mesma, não permitia a participação estudantil nas instâncias deliberativas da Universidade e ignorava seus anseios. (NETO, 2011, p.67).

Impossível admitir que 100 anos após a reforma possamos ver alguma semeIhança no formato de ensino. Com objetivo de aplicar os objetivos de Córdoba traduzidos para a atualidade, e as concepções de Antunes para o trabalho, a participação estudantil aconteceu durante toda a atividade proposta, sendo, deles, o caminho trilhado. A participação do professor foi como mediador, pois "a autoridade, em uma casa de estudantes, não se exerce mandando, mas sugerindo e amando: ensinando" (NETO, 2011, p.66), contendo a participação de outros professores como banca avaliadora das propostas criadas pelos alunos, no intuito de contribuir com a idealização dos projetos e com a construção do conhecimento. 
Buscando seguir o princípio de indissociabilidade entre ensino, pesquisa e extensão, após observar as compreensões iniciais dos estudantes sobre a práxis da Moda inclusiva, atentos as sugestões obtidas em sala de aula, foi firmada uma parceria com a equipe de para-desporto de Blumenau, que se prontificou a realizar uma palestra com os estudantes expondo as dificuldades dos atletas em relação a vestimenta e hábitos cotidianos.

Isto tornou a proposta instigante, havia pressão, pois, os estudantes percebiam que seu trabalho representava algo valioso para muitas pessoas, mas também curiosidade, por parte dos discentes, nas avaliações sobre suas atuações profissionais.

Três atletas cadeirantes e uma atleta amputada expuseram sua história de vida, falaram sobre como chegaram as suas condições e como chegaram ao para-desporto, contaram sobre o trabalho que o esporte estava fazendo em suas vidas. Este espírito humano aliado ao trabalho foi de fundamental importância para a ressignificação do ofício de designer de Moda. A utilidade da roupa, a sua adequação aos corpos e ao hábito, e a necessidade urgente de adequação da roupa a estas pessoas ressignificava os tão ensinados termos "usabilidade" e "vestibilidade". Ver pessoas reais, expondo condição real da comunidade, e a percepção pessoal dos estudantes relacionando a roupa às necessidades diárias de seu núcleo de convivência transformou o projeto.

Em Abril de 2017, os estudantes participaram de um treino com os para-atletas, convivendo com suas realidades cotidianas. Entrevistaram os atletas cegos, portadores de melingocele, cadeirantes e amputados nas atividades de corrida e arremesso de disco. Houve uma comoção tanto dos atletas, por ter suas necessidades estudadas, quando dos estudantes, ao perceber que havia vinculação de suas ações profissionais às realidades cotidianas.

Os estudantes, então, divididos em grupos de trabalho, debateram sobre as deficiências físicas existentes, para desenvolver uma coleção visando aplicar a utilidade da roupa.

A mudança do curso da atividade ocorreu quando os estudantes passaram a perceber o seu cotidiano, suas realidades vividas. A partir das considerações deles sobre a percepção de pessoas dentro do quadro familiar que eram portadoras de dificuldades motoras, idosos ou pessoas com síndromes diversas, concluíram que a roupa encontrada no mercado era segregadora e excludente, e passaram a questionar estas questões em sala de aula. A proposta então passou a ser desenvolver roupas para pessoas que obtivessem as necessidades observadas, numa seleção minuciosa de aviamentos e tecidos, repensando a forma e a construção da roupa, de forma que servisse para todos os corpos.

A proposta foi apresentada para uma banca de professores, tratava de peças de uma roupa inclusiva que pudesse ser encontrada em qualquer magazine de shopping, proporcionando, além do acesso às pessoas com deficiência, o acesso a pessoas com mobilidade reduzida, devido a condições como Parkinson e artrite reumatoide, a idade avançada e pessoas com doenças severas, como câncer.

Esta parcela não vista das pessoas reais que permeiam nosso cotidiano foram incluídas pelos estudantes a partir das constatações feitas em seu modo de vida, do seu meio de convívio.

Surgiram roupas que fossem adequadas a idosos, pessoas ostomizadas, pes- 
soas com nanismo, amputados diversos, permitindo adequação a todos os corpos, por meio de pequenas modificações na proposta da peça.

Como mangas ou partes de calça que fossem destacáveis, modelagens amplas com modelos que permitissem estética a corpos diversos, fechamentos frontais com proteção para que o zíper não tocasse a pele, puxadores de zíper com cordões para permitir que pessoas com mobilidade reduzida conseguissem utilizar o aviamento.

Os aviamentos foram escolhidos obedecendo critérios de design que respeitassem a necessidade dos usuários, os preferidos foram botões de pressão, botões imantados, velcro, zíper de nylon e plástico e elásticos. O desenvolvimento ocorreu em grupos com apoio da professora, deixando livre a geração de ideias que pudessem ser produzidas nos atuais meios de produção existentes.

Figura 1: Desenvolvimento de coleção em Sala de aula:

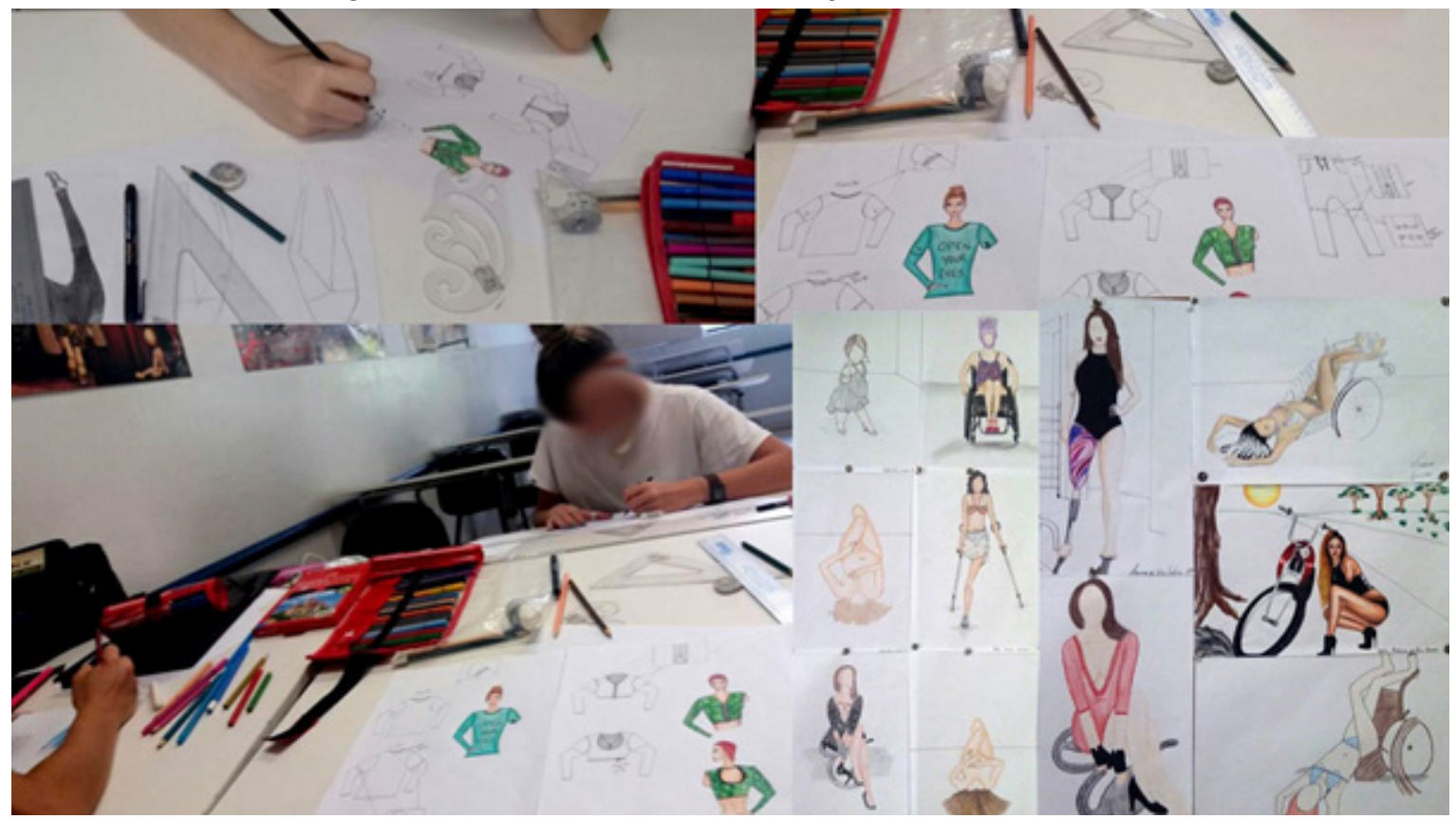

Fonte: Autora.

Figura 2: Peças desenvolvidas

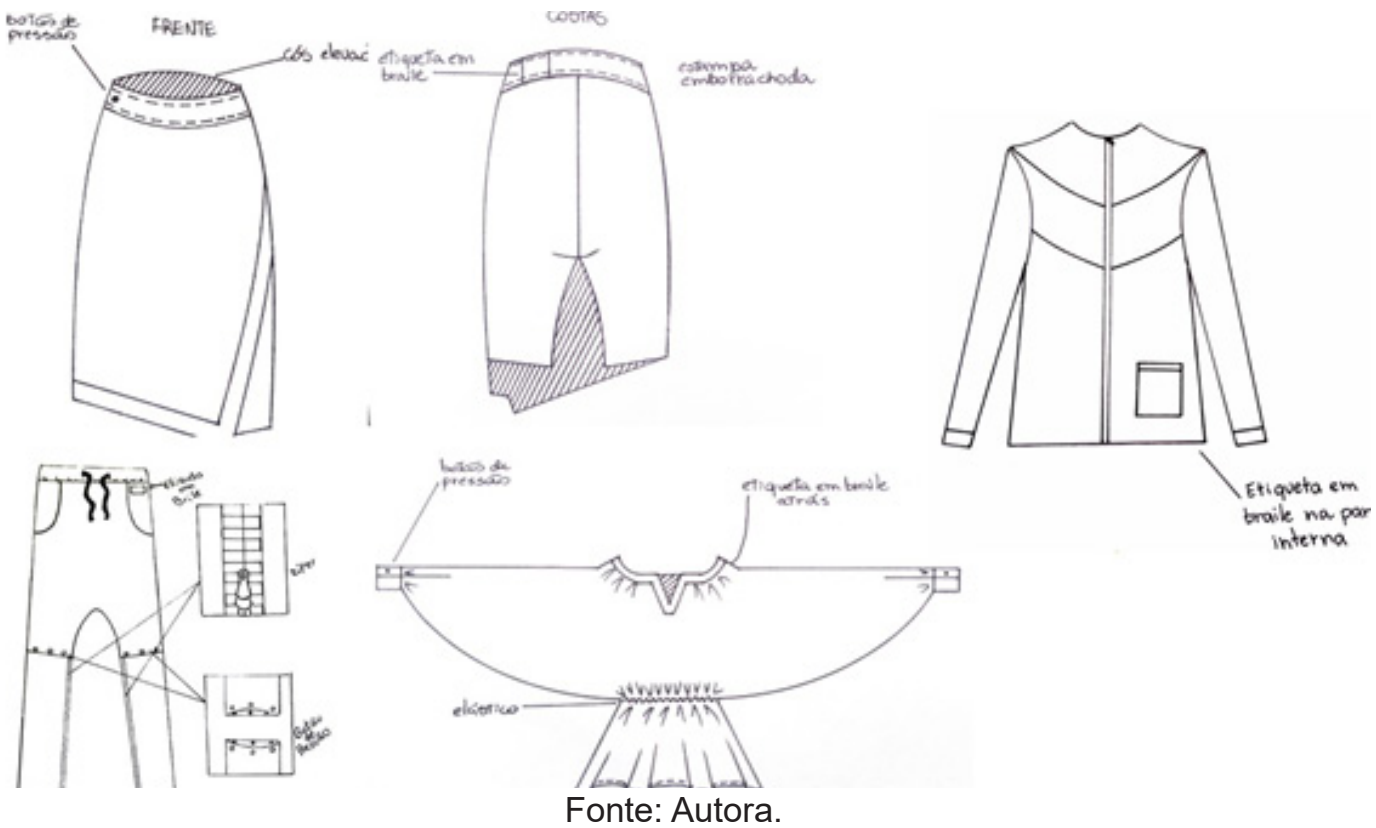


O short saia representado na imagem acima foi criado pensando em aplicar estampa emborrachada na parte traseira da peça, para que a cadeirante não escorregasse da cadeira, uma queixa comum entre as cadeirantes do grupo de para atletas. A calça tem botões nos joelhos, permitindo que possa ser retirada a parte inferior da calça, quando calor, virando um short, ou quando pessoas amputadas necessitassem trocar de prótese, facilitando a ação.

O casaco da imagem foi criado para ser uma peça dupla faze, com zíper imantado, de forma que as etiquetas e estampas teriam dizeres estampados ou bordados em braile, para acessibilidade de cegos, não deixando de ser uma peça interessante para pessoas sem deficiência. A bata foi proposta para reduzir a diferença existente entre a parte de cima do corpo de cadeirantes e a parte de baixo, em virtude do atletismo as cadeirantes do grupo de para desporto tinham braços grandes, e reclamaram da dificuldade em encontrar peças bonitas e práticas, a bata seria fácil de vestir, de se movimentar com ela, reduzindo a diferença estética.

Muitas outras peças foram desenvolvidas, repensando a forma de criar uma roupa, a compreensão dos estudantes foi de que, com recursos já existentes no mercado, e observando as demandas sociais, seria possível produzir peças inclusivas sem alto custo, apenas com adaptações nos aviamentos e modelos que valorizassem mais tipos de corpos.

Foram incluídas nas etiquetas, além da inscrição habitual, a inscrição em braile das informações da peça, utilizando técnicas como a estampa emborrachada, e a criação de símbolos que permitissem aos cegos combinar modelo das peças. Também foram feitos estampas e bordados em braile para que aquela peça fizesse parte do cotidiano de valores do usuário.

Todas as ideias do grupo acerca das modelagens e métodos produtivos eram discutidas com profissionais e usuários para conferir que o produto final cumpriria seu objetivo. Surgiram peças dupla face e short saia, para que a cadeirante pudesse vestir-se socialmente para um evento, ainda com o conforto e a segurança do short.

A apresentação dos produtos ilustrava os objetivos de autonomia e independência para pessoas com deficiência visual, dificuldade motora e distrofia, autonomia e independência nas ações cotidianas, como vestir, despir, trocar de prótese ou adequar-se a mudanças climáticas, com estética e elegância para todas as pessoas cujos corpos obtivessem conforto dentro da roupa.

O trabalho com foco no resultado do produto, fez um processo de reversão da alienação antes observada. A falta de estímulo, provinda da não capacidade de relacionar o produto ao seu fim foi transpassada.

No que diz respeito ao estranhamento no mundo da produção, ao estranhamento econômico, ao processo de fetichização do trabalho e da sua consciência, mantém-se a enorme distância entre o produtor e o resultado do seu trabalho. (ANTUNES, 1995, p.92)

Um quadro que apenas pode ser modificado pela educação consciente, de onde podemos retirar da reforma de Córdoba seus principais anseios:

sintetizada nos seguintes pontos: coparticipação dos estudantes na estrutura, administrativa; participação livre nas aulas; periodicidade definida e professorado livre das cátedras; caráter público das sessões e instâncias administrativas; extensão da Universidade para além dos seus limites e difusão da cultura univer- 
sitária; assistência social aos estudantes; autonomia universitária; universidade aberta ao povo. (NETO, 2011, p.67).

A atividade nos permitiu, como docentes, discentes, pedagogos e corpo administrativo promover a reforma diária de nossas concepções de ensino, e como criadores, em nossas concepções sobre mundo, cultura e público.

Durante a finalização do projeto, surgiu a oportunidade de inserir a proposta em um evento estadual de inovação, de nome INOVASC, que registra demandas sociais e ideias geradas em sala que venham a suprir estas demandas. Um grupo representante foi inscrito, participando da apresentação com um produto confeccionado. O objetivo não foi o de competir, mas de transferir o conhecimento, levar a ideia até os produtores de vestuário para que pudessem também compreender a inclusão. O projeto inscrito recebeu o primeiro lugar, seguindo para a etapa nacional.

Este processo marcou o final de um ciclo de ensino de seis meses, e o início de um ciclo constante de vivências e experiencializações conscientes, críticas, na formação de profissionais que tenham a capacidade de racionalizar a própria ação.

\section{CONCLUSÃO}

A indissociabilidade entre ensino (mediação do professor), pesquisa (de campo e do cotidiano dos estudantes) e extensão (divulgação do conhecimento gerado) provou-se tanto possível quanto regeneradora, desejada e necessária. Sem a qual o processo de ensino se encontra dissolvido nas premissas do trabalho sem objetivo, sem função e sem aplicação social.

Muitas vezes a estética da peça se reduz a tantos bolsos sem utilidade, tantos zíperes, bordados e estampas sem função, que, com pequenas alterações na peça, mas com profundas alterações na forma de pensar a criação de produtos de Moda, foi possível inovar a vestimenta visando a responsabilidade social do trabalho, a emancipação do discente como profissional, e a democratização do objeto de estudo.

Educar para uma Moda que contemple mais o real e menos o imaginário, em instituições abertas ao povo e integradas em sua comunidade, nos permite amadurecer as concepções de trabalho, profissionalizando o ser para a esfera social, local e global, conhecedor de sua função e permitindo que este seja gerador, transformador e integralizador de conhecimento.

Após conquistas cunhadas em lutas, como a reforma de Córdoba, e das transformações mundiais do trabalho e da classe que vive do trabalho, tratadas por Antunes (1995), repensar a forma como idealizamos o ser social e as funções cotidianas mostra-se um trabalho diário, pertinente a todo profissional consciente e crítico de sua posição e função social.

Nesta atividade, os resultados foram além dos esperados, a autoria e participação de uma turma então desmotivada tornou-se nítida, o aprendizado foi alcançado a tal ponto que os desenvolvimentos propostos conseguiram atingir excelência em um concurso estadual. Mostra que, ao invés de passar conteúdo devemos trabalhar para a geração do conhecimento, questionando e promovendo a possibilidade de mudança. Ao invés de trabalharmos, enquanto docentes, para o ensino apenas técnicos para o mundo do trabalho, devemos compreender que o trabalho é social, que o criador cria para o ser 
humano em todas as suas necessidades físicas, psicológicas e biológicas.

Diminuiríamos assim a dificuldade em andar, levantar, sentar, vestir, despir, e várias outras ações humanas que representam, justamente, os conceitos do design.

\section{REFERÊNCIAS}

ANTUNES, Ricardo. Adeus ao Trabalho? Ensaio Sobre as Metamorfoses e a Centralidade do Mundo do Trabalho. São Paulo: Cortez, ed.16, 2015a.

ANTUNES, Ricardo. Serv. Soc. Soc., São Paulo, n. 124, p. 773-799, out./dez. $2015 b$. Entrevista concedida a Claudia Mazzei Nogueira e Maria Liduína de Oliveira e Silva.

ANTUNES, Ricardo. Adeus ao trabalho? Ensaio sobre as metamorfoses e a centralidade do mundo do trabalho. 3ed. São Paulo: Cortez, 1995.

CMI. Manifesto de Córdoba, 1918 - Reforma universitária. 2007. Disponível em < https://midiaindependente.org/pt/blue/2007/10/399447.shtml>. Acesso em 20.07.2018.

DELGADO, Daniela. Configurações sobre a educação no setor de Moda. Revista lara, São Paulo - V.3 N³ dez. 2010 - Dossiê.

FRANK, A.; FUENTES, M.1989. Dez teses acerca dos movimentos sociais. Lua nova, São Paulo, n. 17, p. 19-49, Jun. 1989.

NETO, José Alves de Freitas. A reforma universitária de Córdoba (1918): um manifesto por uma universidade latino-americana. Revista Ensino Superior Unicamp, São Paulo, p. 62-70. Mai.2011.

PIRES, Dorotéia Baduy. Design de Moda: uma nova cultura. Revista Dobras, Estação das Letras, V.1, n.1, p.75-82, Out. 2007.

SANTOS, Heloísa. Moda e economia criativa: Perspectivas globais e relações locais. In: $10^{\circ}$ COLÓQUIO DE MODA - $7^{\circ}$ EDIÇÃO INTERNACIONAL - $1^{\circ}$ CONGRESSO BRASILEIRO DE INICIAÇÃO CIENTÍFICA EM DESIGN E MODA, 2014, Caxias do Sul. Anais do $10^{\circ}$ Colóquio de Moda Gt9, ISSN 1982-094I. Disponível em http://www.coloquiomoda. com.br/anais/Coloquio\%20de\%20Moda\%20-\%202014/ARTIGOS-DE-GT/GT09-MODA-E-GLOBALIZACAO/GT-9-Moda-e-economia-criativa_perspectivas-globais-e-relacoes-locais.pdf. Acesso em 15.08.2018 